\title{
Consecutive Radiography of Breast Slices for Estimation of Glandular Volume and Detection of Small Subclinical Lesions. A Comparison between Japan and Hawaii Japanese
}

\author{
Nobuaki Sasano, Nobuaki Tamahashi, T'suneo Namiki* \\ and Grant N. Stemmermann $\dagger$ \\ Department of Pathology, Tohoku University School of Medicine, \\ Sendai, National Sendai Hospital,* Sendai, and Japan Hawaii \\ Cancer Study, Kuakini Hospital, $\uparrow$ Honolulu, Hawaii, U.S.A.
}

\begin{abstract}
Sasano, N., Tamahashi, N., Namiki, T. and Stemmermann, G.N. Consecutive Radiography of Breast Slices for Estimation of Glandular Volume and Detection of Small Subclinical Lesions. A Comparison between Japan and Hawaii Japanese. Tohoku J. exp. Med., 1975, 117 (3), 217-224 — A technique of consecutive radiography of the serially sliced breast was evolved and applied to a comparative study on the breast of Japanese in Japan ( 75 subjects) and Hawaii (49). Increased mammary fat accounts for an increase in the size of the Hawaii Japanese breast (mean; $152.4 \mathrm{~cm}^{3}$ ) in comparison with that in Japan $\left(82.5 \mathrm{~cm}^{3}\right)$. However, the glandular volume calculated from the radiographs and lobular structures in histology were not significantly different in the two groups. A small subclinical lesion measuring over $3 \mathrm{~mm}$ in diameter in a histological section was radiographically detected. In Hawaii, duct-epithelial hyperplasia and apocrine metaplasia were significantly more prevalent than in Japan, and the former lesion was most conspicuous in the large mammary gland. —— slicespecimen mammography; glandular volume; duct-epithelial hyperplasia; apocrine metaplasia
\end{abstract}

A mammographic survey for breast cancer detection by Stevens and Weigen (1966) revealed 8 unsuspected carcinomas in 1,223 clinically normal women over 40 years of age. Not all malignant lesions, however, were demonstrated in mammograms and the diagnostic accuracy for a small lesion of lobular carcinoma in situ was generally poor (Hutter et al. 1969). Rosen et al. (1974) emphasized the value of specimen radiography of the breast during surgery to facilitate the diagnosis of minimal lesions by the presence of calcification. Radiographic, subgross and microscopic examinations of whole breast slices were useful for revealing small lesions (Hutter and Kim 1971), but no attempt was made at a specimenradiographic survey for breast volume. The present authors have evolved a simple

Received for publication, June 18, 1975.

This work was supported by Public Health Service Contract No. 1 CP 23213 from the National Cancer Institute and by a Grant-in-Aid for Cancer Research from the Japanese Ministry of Health and Welfare, and by NCI Contract \# NIH-NCI-E-72-2170 to the Japan Hawaii Cancer Study, Kuakini Hospital. 
radiographic technique of the serially sliced breast for a survey of clinically unsuspected small breast lesions and applied it to volume estimation of the mammary gland. The technique has been used to conduct a comparative study of the breast at necropsy of Japanese women in Japan and Hawaii. The purpose of this investigation is to determine whether or not any significant structural difference in the non-cancerous sections of normal breast exists between the Hawaii Japanese who are at intermediate risk of breast cancer and the indigenous Japanese who are at low risk.

\section{Materials aNd Methods}

The whole left breast was enucleated subcutaneously from women at autopsy and was fixed in $10 \%$ formalin as a whole. The specimens were obtained from cases not selected but random in numerical order from the onset of the study. None of the specimens had any grossly apparent masses or abnormalities prior to sectioning.

The materials tested were the breast obtained from 75 cases in Japan and 49 in Hawaii, in which 16 from Japan and 1 from Hawaii were younger than 40 years old and 6 from Japan and 24 from Hawaii were over 70 years old. The materials in Hawaii were obtained from Issei and Nisei patients at the Kuakini Hospital, Honolulu, U.S.A. and those in Japan were obtained at the Department of Pathology, Tohoku University School of Medicine, Sendai, Japan. All of the subsequent tissue preparations were done at Tohoku University. The causes of death in the two groups are summarized in Table 1.

The whole breast was sagittally cut into serial slices $3 \mathrm{~mm}$ thick using a ham-slicer (Fig. 1 left). All slices were arranged in numerical order and radiographed by an ultrasoft X-ray (Softex ESM) on Fuji Softex Film FG. The shadows of mammary gland and surrounding tissue in each slice were traced on a section paper. In order to distinguish the breast from the surcounding fat, an artificial borderline was drawn $10 \mathrm{~mm}$ outside the shadow of mammary gland (Fig. 1, right). Areas of the glandular shadow and the breast fat in each slice were then measured separately (Fig. 2). The volume of mammary gland and the total volume of breast were calculated by the following formula:

volume of mammary gland $=\mathbf{3} \cdot \sum_{i=1}^{n} M_{i}$

total volume of breast $=3 \cdot \sum_{i=1}^{n}\left(M_{i}+F_{i}\right)$

$M_{i}$ : area of the shadow of mammary gland in a radiogram of slice No. $i$.

$F_{i}$ : area of a shadow of fat tissue in the radiogram of slice No. $i$.

For histological estimations, 55 Japan eases and 49 Hawaii cases were available. Paraffin sections were made from more than 10 slices of each individual breast and were stained with hematoxylin and eosin and with elastica-Masson. Abnormal findings in radiograms were compared with those in histology. The development of the lobular structure and the histological grading of periductal fibrosis were roughly estimated.

\section{Results}

As shown in Fig. 3, the total volume of breast in Hawaii cases had a wide range with the mean of $152.4 \mathrm{~cm}^{3}$ and the volume tended to decrease with aging; on the other hand, Japan cases generally had a narrow range around the mean of $82.5 \mathrm{~cm}^{3}$. The total volume of breast was examined with respect to the ratio of body weight to body height (Fig. 4). The majority of Japan cases had the ratio between 0.2 and 0.4 , and the breast volume was less than $200 \mathrm{~cm}^{3}$ in all 
Tissue Mammography of Japan and Hawaii Japanese

TABLE 1. Causes of death

\begin{tabular}{lcc}
\hline \multicolumn{1}{c}{ Diseases } & Japan & Hawaii \\
\hline Breast cancer & 21 & 4 \\
Other malignancy & 24 & 24 \\
Cardio- and cerebro-vascular & 5 & 14 \\
$\quad$ disease & 2 & 0 \\
Puerperal shock & 23 & 7 \\
Miscellaneous & & 49 \\
Total & 75 & 49 \\
\hline
\end{tabular}

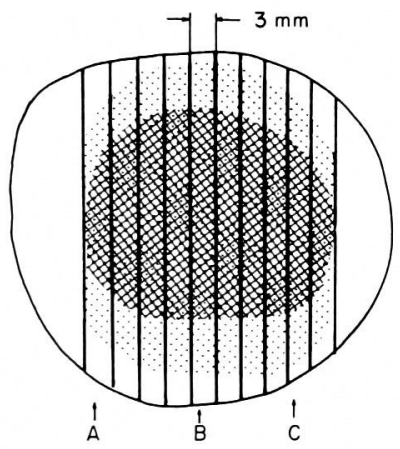

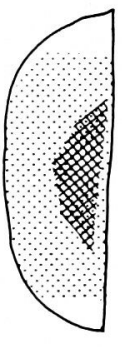

A

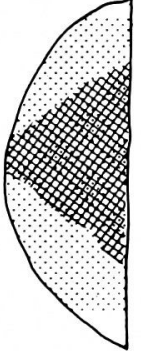

B

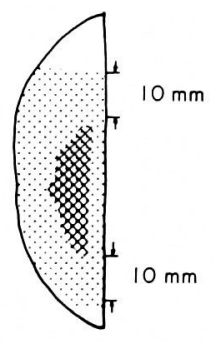

C

mammary gland.

Fig. 1. Schema for cutting and volume measurements of the breast.

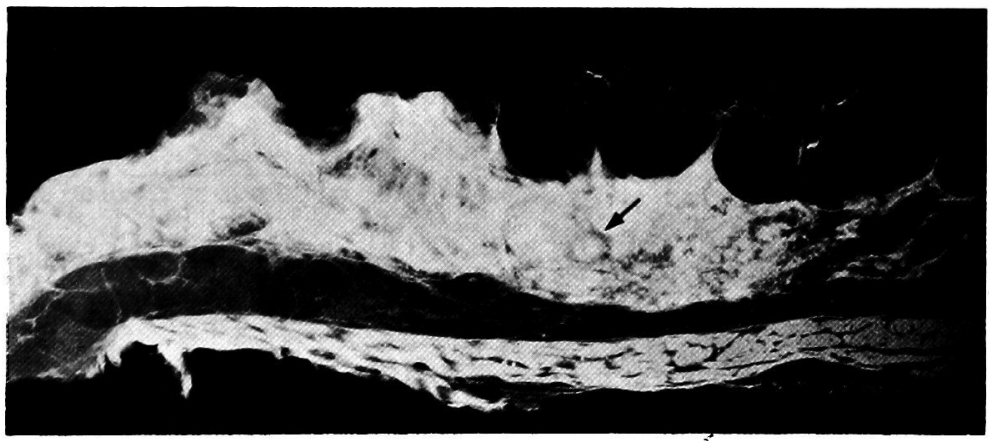

Fig. 2. A tissue radiogram of a breast slice from a case 48 years of age (J. 72-029). Arrow indicates a lesion of sclerosing adenosis.

but 2 cases and had no relationship with the ratio of body weight to body height. In contrast to the Japan cases, almost half of the Hawaii cases showed the ratio of 0.4 or more, and only 4 cases had the ratio of less than 0.3 . The breast volume tended to parallel the ratio of body weight to body height. 

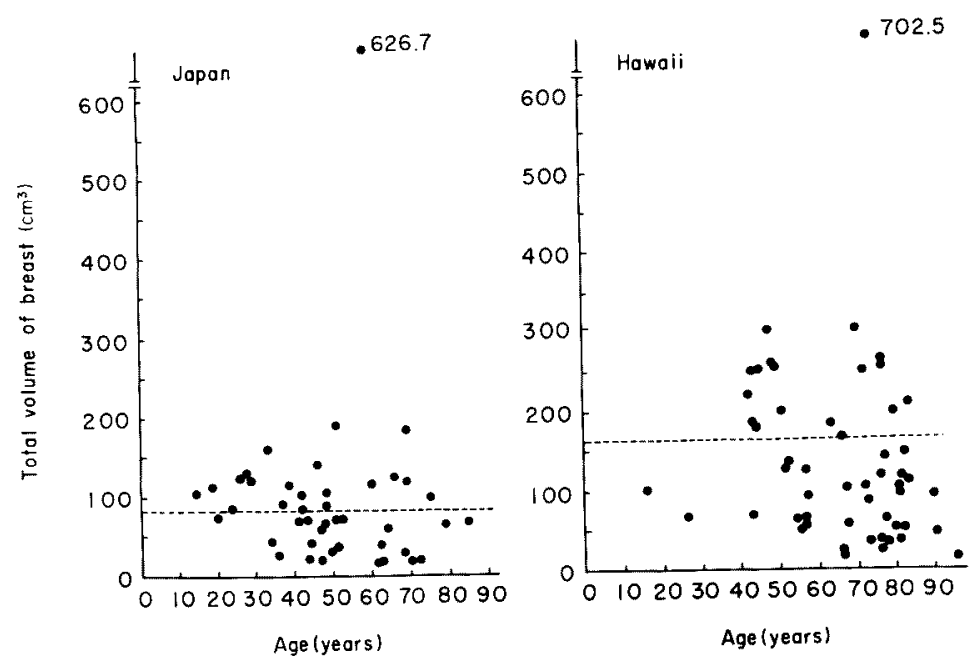

Fig. 3. Total volume of breast by age. The dotted line indicates the mean volume.
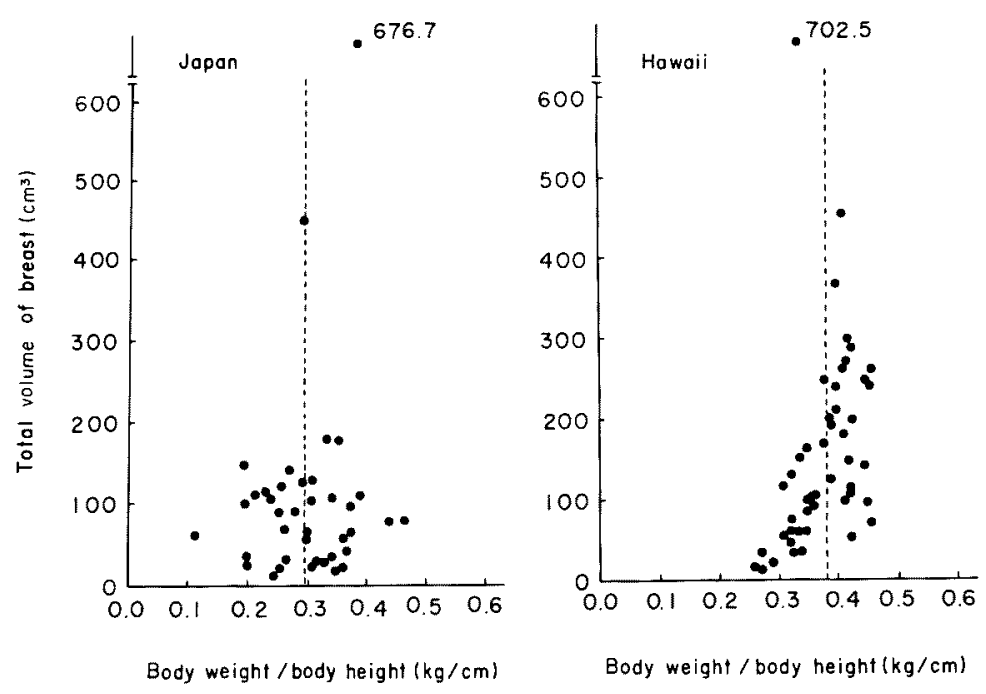

Fig. 4. Total volume of breast by body weight/height ratio. The dotted line indicates the mean ratio.

It was suggested by Fig. 4 that large breasts in Hawaii cases might depend on obesity. Therefore, the volume of mammary gland was examined in relation to age (Fig. 5). Both Japan and Hawaii cases showed a decrease in the volume of mammary gland with aging. Although Japan cases older than 70 years were few, they showed in general a smaller mammary volume than that in the same age group in Hawaii. Histological grading of the development of lobular structure gave no significant difference between both sources.

The volume of mammary gland was examined with respect to causes of death. 


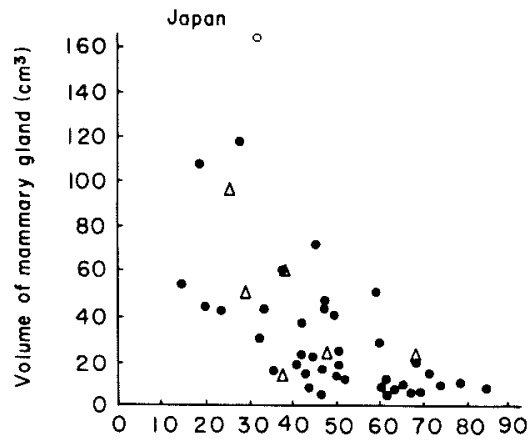

Age (years)

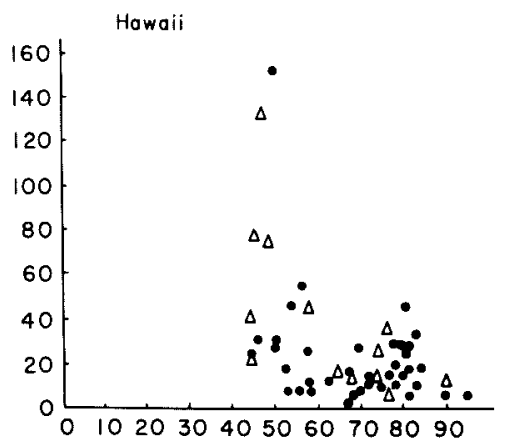

Age (yeors)

Fig. 5. Volume of mammary gland by age and proliferative lesions. $\circ$, pregnancy; $\Delta$, with proliferative lesions; •, without remarkable changes.

T ABLE 2. Comparison of breast histology between Japan and Hawaii

\begin{tabular}{lccccc}
\hline & $\begin{array}{c}\text { Number of cases } \\
\text { examined }\end{array}$ & $\begin{array}{c}\text { Breast } \\
\text { carcinoma }\end{array}$ & $\begin{array}{c}\text { Epithelial } \\
\text { hyperplasia }\end{array}$ & $\begin{array}{c}\text { Apocrine } \\
\text { metaplasia }\end{array}$ & $\begin{array}{c}\text { Intraductal } \\
\text { calcification }\end{array}$ \\
\hline Japan & 55 & 0 & 6 & 5 & 4 \\
Hawaii & 49 & 0 & 14 & 19 & 5 \\
Total & 104 & 0 & 20 & 24 & 9 \\
\hline
\end{tabular}

TABLE 3. Age distribution of histologic patterns of breast

\begin{tabular}{|c|c|c|c|c|c|c|c|c|}
\hline \multirow{2}{*}{ Age } & \multicolumn{2}{|c|}{$\begin{array}{c}\text { Number of cases } \\
\text { examined }\end{array}$} & \multicolumn{2}{|c|}{$\begin{array}{c}\text { Epithelial } \\
\text { hyperplasia }\end{array}$} & \multicolumn{2}{|c|}{$\begin{array}{l}\text { Apocrine } \\
\text { metaplasia }\end{array}$} & \multicolumn{2}{|c|}{$\begin{array}{l}\text { Intraductal } \\
\text { calcification }\end{array}$} \\
\hline & Japan & Hawaii & Japan & Hawaii & Japan & Hawaii & Japan & Hawaii \\
\hline $0-19$ & 2 & 1 & 0 & 0 & 0 & 0 & 0 & 0 \\
\hline $20-29$ & 6 & 0 & 2 & 0 & 0 & 0 & 1 & 0 \\
\hline $30-39$ & 8 & 0 & 2 & 0 & 0 & 0 & 0 & 0 \\
\hline $40-49$ & 13 & 8 & 1 & 5 & 0 & 4 & 2 & 1 \\
\hline $50-59$ & 8 & 9 & 0 & 1 & 1 & 2 & 0 & 1 \\
\hline $60-69$ & 12 & 7 & 1 & 2 & 2 & 3 & 1 & 1 \\
\hline $70-79$ & 5 & 12 & 0 & 5 & 2 & 6 & 0 & 1 \\
\hline $80-$ & 1 & 12 & 0 & 1 & 0 & 4 & 0 & 1 \\
\hline Total & 55 & 49 & 6 & 14 & 5 & 19 & 4 & 5 \\
\hline
\end{tabular}

Malignant tumors and cardiovascular diseases predominated after 40 years of age, but neither of them showed any mentionable relation with the volume of mammary gland. A few cases of oophorectomy showed a small volume of mammary gland.

Next, the volume of mammary gland was examined with respect to the presence of epithelial hyperplasia (Fig. 5). In Japan, cases of pregnancy naturally had a large volume, but cases of localized epithelial hyperplasia showed no volumetric peculiarity. In Hawaii, subjects younger than 60 years with a large 
Table 4. Cases with proliferative lesions

\begin{tabular}{|c|c|c|c|}
\hline Patient & $\begin{array}{c}\text { Age } \\
\text { (years) }\end{array}$ & Histologic diagnosis of breast & Underlying diseases \\
\hline \multicolumn{4}{|l|}{ (Japan) } \\
\hline 1. $72-062$ & 26 & IDP, moderate & Tuberculous meningitis \\
\hline 2. $72-068$ & 29 & IDP, severe & Subacute encephalitis \\
\hline 3. $71-340$ & 37 & Duet hyperplasia, mild & Mitral insufficiency \\
\hline 4. $73-048$ & 39 & Duct hyperplasia, moderate & Ulcerative colitis \\
\hline 5. $72-029$ & 48 & Sclerosing adenosis, mild & Subarachnoid hemorrhage \\
\hline 6. $73-124$ & 69 & IDP, mild & Cerebral infarction \\
\hline \multicolumn{4}{|l|}{ (Hawaii) } \\
\hline 1. $73-\mathrm{A}-031$ & 43 & IDP, moderate & Ovarian carcinoma \\
\hline 2. $73-\mathrm{A}-101$ & 44 & IDP, moderate & Pulmonary carcinoma \\
\hline 3. $72-\mathrm{A}-099$ & 45 & IDP, moderate & Malignant histiocytosis \\
\hline 4. $72-\mathrm{A}-104$ & 46 & Myoepithelial hyperplasia, severe & Acute leukemia \\
\hline 5. $72-\mathrm{A}-132$ & 48 & IDP, severe & Myocardial infarction \\
\hline 6. $73-\mathrm{A}-009$ & 57 & IDP, mild & Gastric carcinoma \\
\hline 7. $72-\mathrm{A}-009$ & 64 & IDP, mild & Atherosclerosis \\
\hline 8. $72-A-086$ & 67 & Fibroadenomatous lesion, microscopic & Gastric carcinoma \\
\hline $9.73-\mathrm{A}-115$ & 72 & IDP, moderate & Pulmonary embolism \\
\hline 10. $72-\mathrm{A}-012$ & 73 & IDP, moderate & Atherosclerosis \\
\hline 11. $72-A-107$ & 75 & IDP, mild & Myocardial infarction \\
\hline 12. $72-\mathrm{A}-074$ & 78 & IDP, moderate & Thyroid carcinoma \\
\hline 13. $73-\mathrm{A}-038$ & 78 & IDP, mild & Pancreatic carcinoma \\
\hline 14. $72-\mathrm{A}-045$ & 93 & IDP, mild & Cerebral infarction \\
\hline
\end{tabular}

IDP : Intraductal papillomatosis.

volume of mammary gland had localized epithelial hyperplasia more frequently than those with a small volume. This corroborated our impression in histologicalexaminations that epithelial hyperplasia was frequently found in the breast with remarkable interlobular fihrosis, while rarely in the fatty breast.

The present method of specimen mammography is useful for surveying small subclinical lesions. Even a psammoma-like calcification of very small size was accurately observed in X-ray film and was histologically confirmed to be intraductal. A localized epithelial hyperplasia was radiographically detected if it measured over $3 \mathrm{~mm}$ in diameter in a histological section.

Histological patterns of localized lesions in the total 104 breasts were summarized in Table 2. No carcinomas were found. Materials from Hawaii were fewer than those from Japan, but epithelial hyperplasia and apocrine metaplasia were found more frequently in the former than in the latter.

Age distribution of various breast lesions was examined (Table 3). Proliferative lesions with epithelial hyperplasia in cases older than 40 years were observed in only $2(5 \%)$ of 39 Japan cases and $14(29 \%)$ of 49 Hawaii cases. In Hawaii apocrine metaplasia appeared after 40 years old in $19(39 \%)$ of 49 cases, while in Japan it was observed after 50 years old in $5(19 \%)$ of 26 cases. Cases of intraductal psammoma-like calcification were small in number and showed no significant difference between the two sources.

Cases of duct-epithelial hyperplasia were listed in Table 4. Intraductal 
papillomatosis was observed in 3 out of 55 cases $(6 \%)$ in Japan and in 12 out of 49 cases $(25 \%)$ in Hawaii. There was no correlation with diseases.

\section{Discussion}

Consecutive radiography of breast slices has been found to be useful for the estimation of glandular volume and the detection of small benign and malignant lesions. We applied this method to comparison of the breasts of Japanese in Japan and Hawaii. According to Segi and Kurihara (1972), breast cancer is an infrequent cause of death among Japanese women as compared with women in western countries. Doll et al. (1970) demonstrated similar differences in the morbidity of this tumor and noted that the morbidity rate of breast cancer in Hawaii Japanese women is intermediate between those of native Japanese and American whites.

The breast of Japanese in Hawaii was generally larger in size than that in Japan, but its glandular volume and histological development of the lobular structure did not differ significantly from that in Japan between 40 and 70 years of age. Therefore, the large volume of the breast of Hawaii Japanese seemed to be due to adipose tissue. This would be consistent with comparative study of Japanese which demonstrated a larger amount of subcutaneous fat in Hawaii subjects (Kagan et al. 1974). However, further observations on more cases over 70 years in Japan and below 40 years in Hawaii will be required to confirm this.

Our method of specimen radiography revealed areas of epithelial hyperplasia measuring $3 \mathrm{~mm}$ or more in diameter as well as very small areas of calcification. Preliminary findings suggest that the Japanese in Hawaii has a higher incidence of proliferative lesions of the ductal epithelium and apocrine metaplasia than the Japanese in Japan, especially in patients over 40 years of age. In Hawaii cases below 60 years of age, duct-epithelial hyperplasia was often found in breasts with large glandular volume. Humphrey and Swerdlow (1966) emphasized a high incidence of large duct epithelial hyperplasia in association with carcinoma of the breast. No carcinoma was detected in the present study, but it may appear if more cases are examined.

\section{References}

1) Doll, R., Muir, C. \& Waterhouse, J. (1970) Cancer Incidence in Five Countries, Springer Verlag, New York, pp. 356-357.

2) Humphrey, L.J. \& Swerdlow, M. (1966) Histologic changes in clinically normal breast at postmortem examination. Arch. Surg., 92, 192-193.

3) Hutter, R.V.P., Snyder, R.E., Lucas, J.C., Foote, F.W. \& Farrow, J.H. (1969) Clinical and pathologic correlation with mammographic findings in lobular carcinoma in situ. Cancer, 23, 826-839.

4) Hutter, R.V.P. \& Kim, D.U. (1971) The problem of multiple lesions of the breast. Cancer, 28, 1591-1607.

5) Kagan, A., Harris, B.R., Winkelstein, W., Jr., Johnson, K.G., Kato, H., Syme, S. L., Rhoads, G.G., Gay, M.L., Nichaman, M.Z., Hamilton, H.B. \& Tillotson, J. (1974) Epidemiologic studies of coronary heart disease and stroke in Japanese men living in 
Japan, Hawaii and California. Demographic, physical, dietary and biochemical characteristics. J. chron. Dis., 27, 345-364.

6) Rosen, P.P., Snyder, R.E. \& Robbins, G. (1974) Specimen radigoraphy for nonpalpable breast lesions found by mammography: procedures and results. Cancer, 34, 2028-2033.

7) Segi, M. \& Kurihara, M. (1972) Cancer Mortality for Selected Sites in 24 Countries. No. 6, Japan Cancer Society, Tokyo, pp. 112-113.

8) Stevens, G.M. \& Weigen, J.F. (1966) Mammography survey for breast cancer detection. A 2-year study of 1,223 clinically negative asymptomatic women over 40 . Cancer, 19, 51-59. 